\title{
Comparative analysis of sex chromosomes in Leporinus species (Teleostei, Characiformes) using chromosome painting
}

\author{
Patrícia Pasquali Parise-Maltempi ${ }^{{ }^{*}}$, Edson Lourenço da Silva ${ }^{1}$, Willem Rens ${ }^{2}$, Frances Dearden ${ }^{2}$, Patricia CM O'Brien², \\ Vladimir Trifonov ${ }^{3}$ and Malcolm A Ferguson-Smith ${ }^{2}$
}

\begin{abstract}
Background: The Leporinus genus, belonging to the Anostomidae family, is an interesting model for studies of sex chromosome evolution in fish, particularly because of the presence of heteromorphic sex chromosomes only in some species of the genus. In this study we used W chromosome-derived probes in a series of cross species chromosome painting experiments to try to understand events of sex chromosome evolution in this family.

Results: W chromosome painting probes from Leporinus elongatus, L. macrocephalus and L. obtusidens were hybridized to each others chromosomes. The results showed signals along their $W$ chromosomes and the use of L. elongatus W probe against L. macrocephalus and L. obtusidens also showed signals over the Z chromosome. No signals were observed when the later aforementioned probe was used in hybridization procedures against other four Anostomidae species without sex chromosomes.

Conclusions: Our results demonstrate a common origin of sex chromosomes in L. elongatus, L. macrocephalus and L. obtusidens but suggest that the L. elongatus chromosome system is at a different evolutionary stage. The absence of signals in the species without differentiated sex chromosomes does not exclude the possibility of cryptic sex chromosomes, but they must contain other Leporinus W sequences than those described here.
\end{abstract}

Keywords: FISH, Zoo-FISH, Microdissection, Sex chromosome evolution

\section{Background}

The origin and evolution of sex chromosomes have interested evolutionary biologists for a long time. Although sex chromosomes evolve from an autosomal pair [1], over time they become different both in gene content and structure [2]. While sex chromosomes in most mammals are ancient, sex chromosomes in some fish, insects and dioecious plants are evolutionarily young $[2,3]$.

Among vertebrates, fish present an enormous diversity of sex determination mechanisms, contrasting with the much more stable systems found in mammals and birds. The majority of teleost fish are gonochoristic, meaning that they exist as males and females, and the most

\footnotetext{
* Correspondence: parise@rc.unesp.br

'Departamento de Biologia, Laboratório de Citogenética, Instituto de Biociências, Universidade Estadual Paulista "Julio de Mesquita Filho" - UNESP, Rio Claro, Av. 24A, 1515, CEP 13506-900 Rio Claro, SP, Brazil

Full list of author information is available at the end of the article
}

gonochoristic species have genetic sex determination. Beside simultaneous and sequential hermaphroditism, gonochorism in fish is controlled by many forms of sex determination involving genetic and/or environmental factors, although temperature-dependent sex determination might be rarer than previously thought $[4,5]$. Despite a large number of fish species described, only a minor fraction has been thoroughly investigated and their sex determination mechanism unequivocally clarified [6].

Within the fish species with genetic sex determination many variations have been found, ranging from male or female heterogamety to polygenic sex determination. Multiple sex chromosomes, or autosomal modifiers that enhance or antagonize the sex-determining genes on the gonosomes, are quite frequent $[7,8]$. This, together with the fact that even between closely related fish species the sex determination mechanisms can be different [6,9-13],

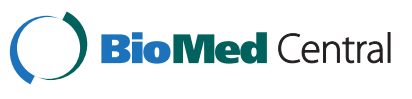


demonstrates the high evolutionary plasticity of this fundamental process [7].

Sex chromosomes in the genus Leporinus (Teleostei, Anostomidae) present some features that make this group very interesting for the study of sex determination mechanisms and sex chromosome structure, composition and evolution. In general, the sex chromosomes of the Leporinus genus have morphological similarities. An exception is observed in the Leporinus sp2 species, where the W chromosomes are not differentiated from autosomes. The Leporinus group consists of around 40 species and eight of them show heteromorphic sex chromosomes and the presence of conspicuous large blocks of heterochromatin on sex chromosomes is the characteristic feature of the Leporinus karyotypes. Among this eight species seven $(L$. conirostris, L. elongatus, L. aff. elongatus, L. macrocephalus, L. obtusidens, $L$. reinhardti, $L$. trifasciatus) possess enlarged W chromosomes in comparison to the $\mathrm{Z}$, due the increase of heterochromatin, while one, Leporinus sp2, presents a karyotype with the $\mathrm{W}$ chromosome equal in size to its homologous $\mathrm{Z}$ and the autosomes. The hypothesis of the accumulation of repetitive elements as the major pathway in the differentiation of sex chromosomes in Anostomidae is widely accepted $[14,15]$. In fact, it has been proposed that repetitive elements are different among some species [16] and that they were probably responsible for the recent origin of a multiple $\mathrm{Z}_{1} \mathrm{Z}_{1} \mathrm{Z}_{2} \mathrm{Z}_{2} / \mathrm{Z}_{1} \mathrm{~W}_{1} \mathrm{Z}_{2} \mathrm{~W}_{2}$ sex chromosome system in L. elongatus [15]. However whether the increase of heterochromatic segments by accumulation of repetitive DNA is the cause or consequence of sex chromosome origin remains, as yet, undiscovered and details of sex chromosome evolution within the genus are unknown.

To study sex chromosome evolution in Leporinus and related Anostomidae species we have obtained whole W chromosome specific probes of three Leporinus species by manual microdissection and used the paints for cross species hybridisation. Our results provide some new views of Anostomidae chromosome evolution and add new evidence on the origin of sex chromosomes in Leporinus.

\section{Results}

Hybridisation using Leporinus elongatus $W$ probe (WLe)

The WLe probe used against chromosomes of the Leporinus elongatus female painted the entire W chromosome (Figure 1a). In female individuals of L. macrocephalus, the WLe probe painted the entire W chromosome as well as a large part of the $\mathrm{Z}$ chromosome (Figure $1 \mathrm{~b}$ ). In male individuals of $L$. macrocephalus the WLe probe painted almost all of both $\mathrm{Z}$ chromosomes (Figure 1d). The WLe probe completely painted the W chromosomes of the female L. obtusidens (Figure 1c). In L. obtusidens males signals were observed in the subtelomeric region of the p-arm of the $\mathrm{Z}$ chromosome, but only after increased exposure time (Figure 1e).

FISH experiments with WLe probes in L. friderici, $L$. striatus, L. lacustris, Schizodon borelii and S. isognathus individuals did not produce any result (even under low stringency wash conditions) (data not shown).

Hybridisation using Leporinus macrocephalus W probe (WLm) FISH experiments using WLm probes showed a hybridisation pattern where the W chromosome of $L$. macrocephalus was entirely painted as well as part of the $\mathrm{Z}$ chromosome (Figure 2a). Also, signals on the long arm of the W1 chromosome of $L$. elongatus and in the W chromosome of L. obtusidens were observed (Figure 2b, c). In L. elongatus male individuals, no hybridisation signals were seen, as in the experiments using the WLe probe onto the $L$. elongatus male.

\section{Hybridisation using Leporinus obtusidens W probe (WLo)}

The WLo probe painted the entire W chromosome of all $L$. obtusidens females (Figure 3a). Signals of similar intensity were also observed in the long arm of W1 chromosomes of L. elongatus and W of $L$. macrocephalus, while signals were absent on the short arm (Figure 3b, c). As it was observed in experiments using W from L. macrocephalus, no signals were detected in male individuals of all analysed species.

\section{Discussion and conclusion}

The W chromosome of Leporinus species is easily recognised, being the largest chromosome of the karyotype due to the accumulation of large heterochromatic blocks, which facilitate the identification of the chromosome during microdissection procedures. While the sex chromosomes of the Leporinus species in general are highly differentiated, the other chromosomes show the typical metacentric- submetacentric pattern [17]. The morphologic similarity among sex chromosomes found in the Leporinus species led to the hypothesis of a common origin, in which an initial accumulation of heterochromatic segments was the first step in the differentiation of sex chromosomes [18]. An exception was found in Leporinus sp2, where the size of the W chromosome was similar to other elements of the karyotype [19]. These authors proposed that the sex chromosomal system in Leporinus sp2 originated independently from the ZW system previously described for other Leporinus species.

Our hybridisation experiments show that WLe hybridizes solely to the W chromosome in L. elongatus, while in $L$. macrocephalus and L. obtusidens the $\mathrm{Z}$ chromosomes were also partly labelled. The WLm and WLo probes reveal a similar result in cross species experiments, the most intense signals being those located at heterochromatic regions of the $\mathrm{q}$ arms. This pattern is possibly due the distribution of repetitive elements. 

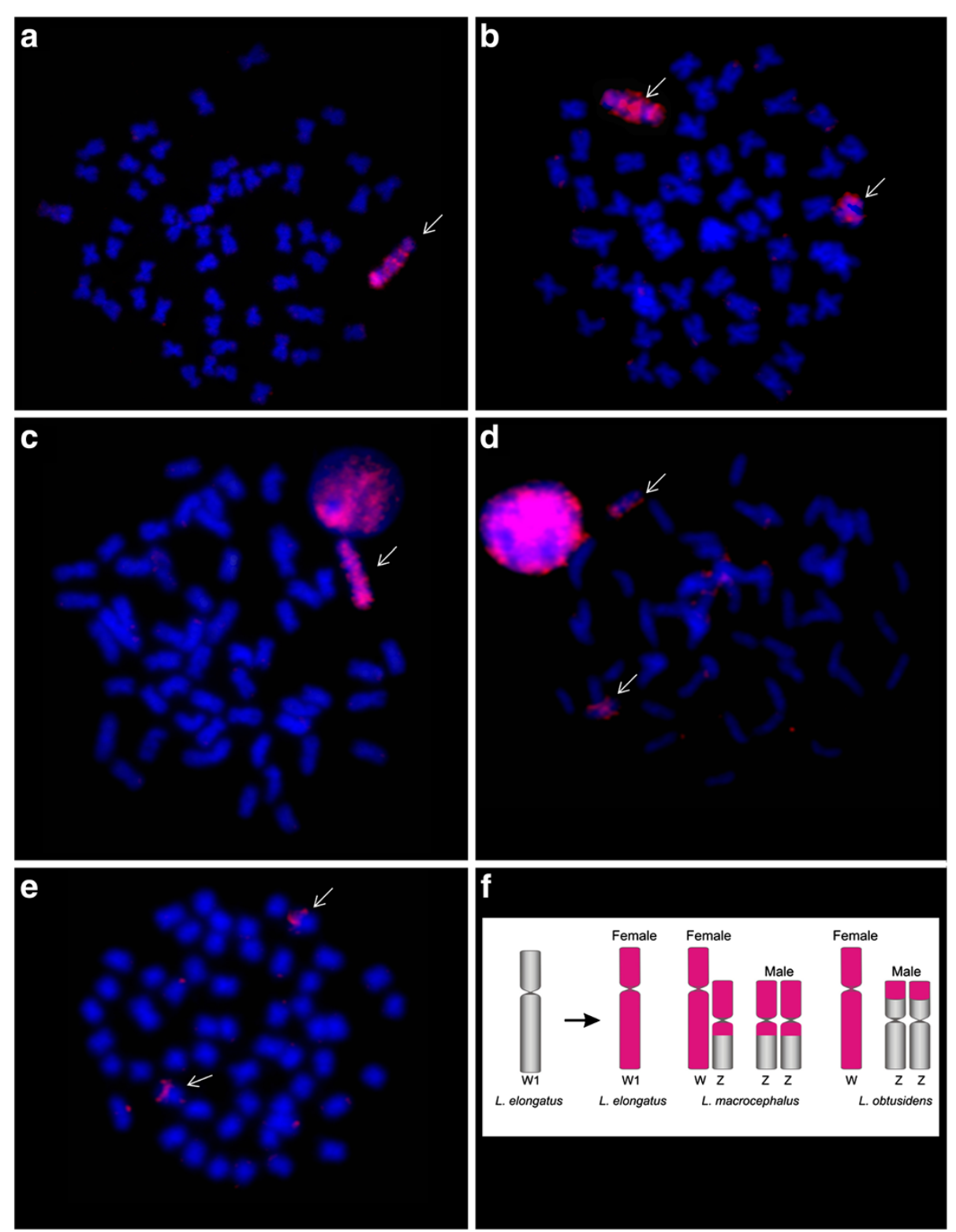

Figure 1 FISH using Leporinus elongatus W chromosome (WLe) probes. a- WLe vs female L. elongatus; $\mathbf{b}$ - WLe vs female L. macrocephalus, c- WLe vs female L. obtusidens; d- WLe vs male L. macrocephalus; e- WLe vs male L. obtusidens; $\mathbf{f}-$ WLe probe hybridisation pattern.

The use of repetitive elements to map the dynamics of sex chromosomes in Anostomidae has been successfully employed. The repetitive element LeSpeI was described as a participant of the sex chromosome differentiation process in L. elongatus [15]. This sequence was also mapped in L. macrocephalus and L. obtusidens, revealing homologies and highlighting their importance in sex chromosome differentiation [20]. However, the attempt to find a relationship between LeSpeI and a putative cryptic sex differentiation process in Leporinus friderici, $L$. striatus, L. lacustris, Schizodon borelii and S. isognathus by mapping this sequence in these species without sex chromosomes, failed because no positive hybridisation signals were observed [21].

The Leporinus genus has been divided hypothetically into two different groups according to cytogenetic and molecular records $[18,22]$. Our data reinforce the idea of the subdivision of Leporinus genus in at least two lineages: one comprising species with differentiated sex chromosomes and the other without sex chromosome differentiation. The W specific probes retrieved from $L$. elongatus, L. macrocephalus and L. obtusidens systematically cross hybridised with other W chromosomes, showing the similarity of these sequences. Based on this fact, it is 


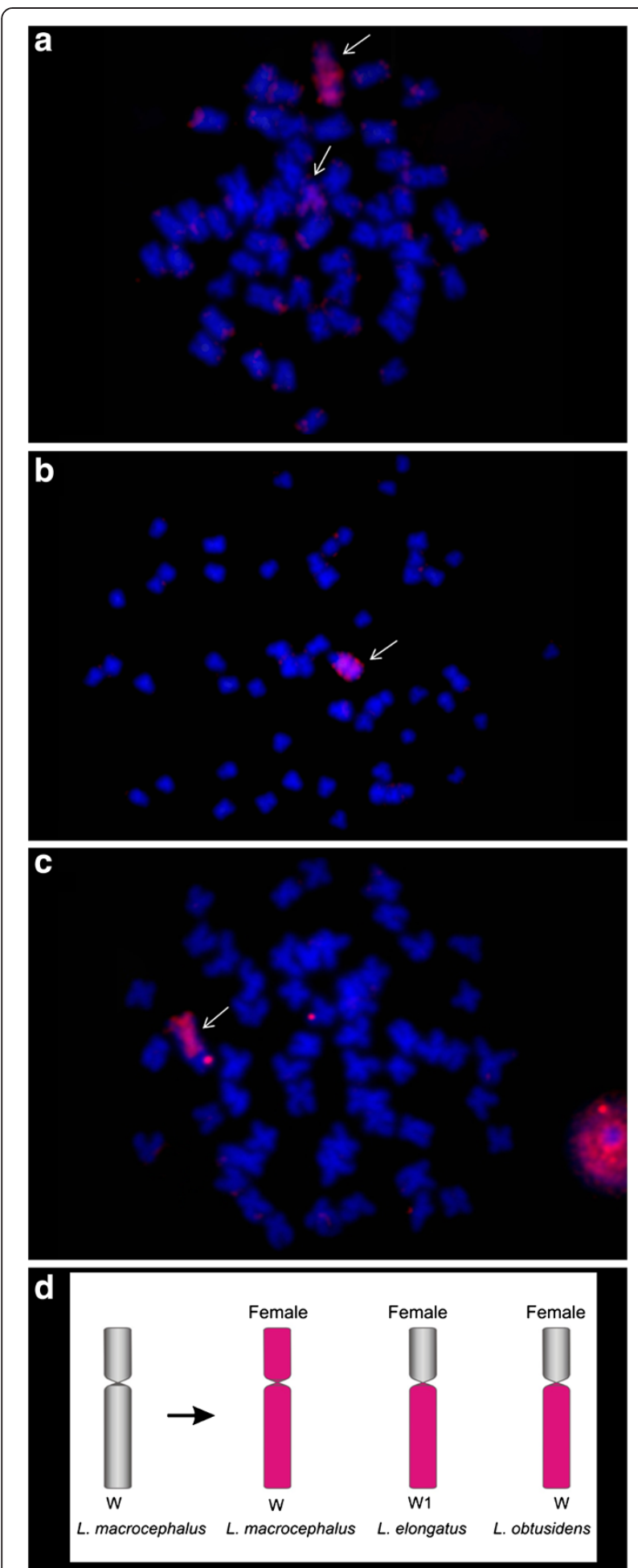

Figure 2 FISH using Leporinus macrocephalus W chromosome (WLm) probes. a- WLm vs female L. macrocephalus; b- WLm vs female L. elongatus; c- WLm vs female L. obtusidens. d- WLm probe hybridisation pattern.

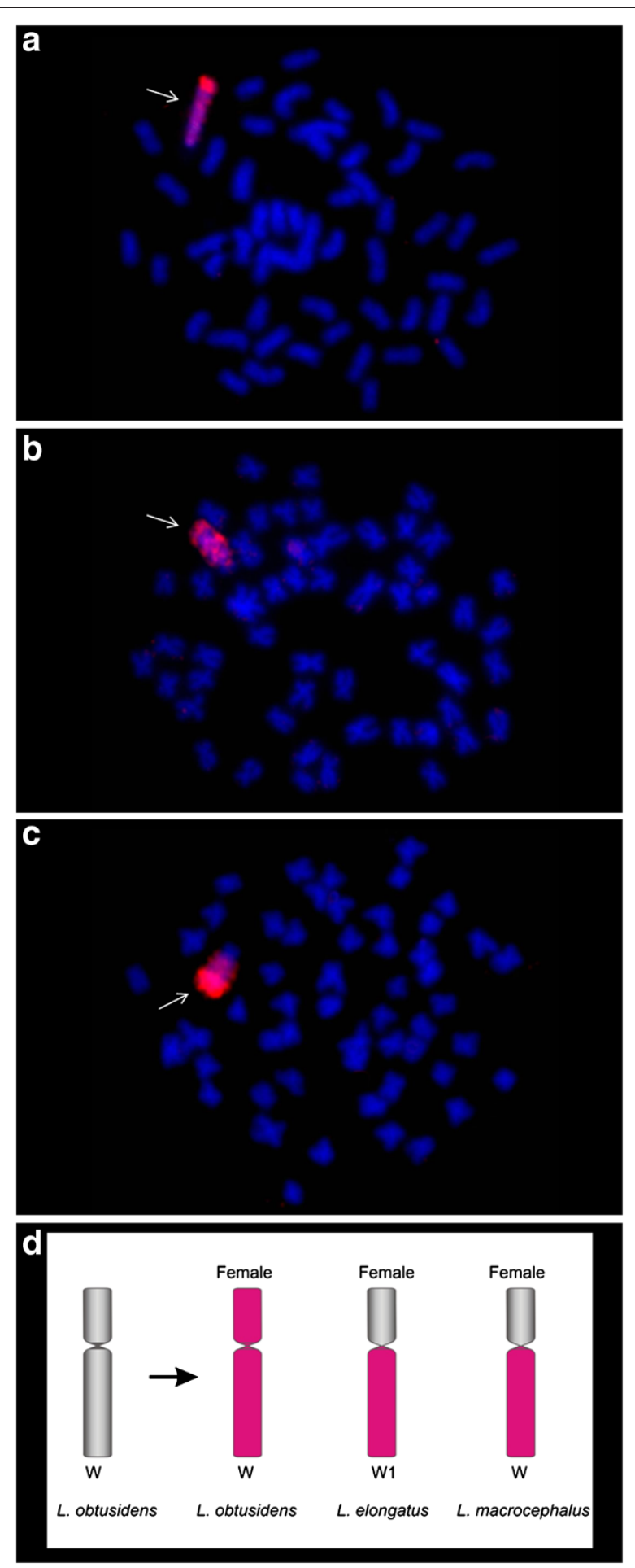

Figure 3 FISH using Leporinus obtusidens W chromosome (WLo) probes. a- WLo vs female L. obtusidens; $\mathbf{b}$ - WLo vs female $L$.

elongatus; c- WLo vs female L. macrocephalus; d- WLo probe hybridisation pattern. 
possible to hypothesize that the sex chromosomes of $L$. elongatus, L. macrocephalus and L. obtusidens had a common origin. According to our results, the hypothesis of cryptic sex chromosomes sharing Leporinus W sequences in the other anostomids (Leporinus friderici, L. striatus, L. lacustris, Schizodon borelii and S. isognathus) can be discarded, consistent with previous studies on repetitive sequences. Furthermore, those sex chromosomes could have originated from the same autosomes, but in a different process of differentiation.

A fact to note in our results is that the probes of the W chromosome from $L$. elongatus paint the $\mathrm{Z}$ chromosome of L. macrocephalus males and females and the $\mathrm{Z}$ chromosome of L. obtusidens male but do not paint the L. elongatus $\mathrm{Z}$ chromosome present in males and females. This reinforces the hypothesis proposed by Parise-maltempi et al. [15] about the presence of a new system of multiple sex chromosomes in L. elongatus. The sex chromosomes of L. elongatus are probably in a different stage of differentiation from those of the other Leporinus species in which repetitive sequences shared between the $\mathrm{Z}$ and $\mathrm{W}$ chromosomes are not shared in L. elongatus chromosome $\mathrm{Z}$.

Cross-species chromosome painting is a powerful tool to delineate syntenic chromosome regions among closely and distantly related species and to reconstruct chromosomal phylogeny [23-25]. In fish specifically, studies have brought new insights into the evolution of sex chromosome systems, and showed that in many cases, closely related groups have taken quite different evolutionary paths [9,10,26-29]. As in Leporinus species analysed in this report, some other fish groups also share a common origin of sex chromosomes [12,30-32].

Our data indicate that in spite of the often reported high plasticity of sex determination mechanisms in fish, in the Anostomidae family, and especially in some species of the Leporinus genus, the sex systems seem to be conserved and derived from a common ancestral pair. Probably the sex chromosomes are actually different, but the different W chromosomes could have been invaded with the same repetitive sequences. The results shown here add new data to studies using the Leporinus genus as a model, reinforcing the hypothesis that the Leporinus ZW sex chromosomes may be found only in closely related species, and remain undetected in the other species.

\section{Methods}

\section{Cell culture and metaphase cell preparation}

Leporinus elongatus chromosomes were obtained from cultured cells. Fibroblast cells collected from fin tissue of $L$. elongatus were cultured in DMEM medium supplemented with 10\% FCS and 50\% Amniomax C-100 (Invitrogen) serum at $37^{\circ} \mathrm{C}$.

The cells were harvested after colcemid treatment (0.05 ug/mL) for 2 hours, suspended in hypotonic solution $(0.075 \mathrm{M} \mathrm{KCl})$ and then incubated at $37^{\circ} \mathrm{C}$ for $20 \mathrm{~min}$. Cells were pelleted and resuspended three times in fresh ice cold fixative (3:1 methanol:acetic acid), then kept at $-20^{\circ} \mathrm{C}$ until use.

The chromosomes of other Anostomidae species (L. friderici, L. striatus, L. lacustris, Schizodon borelii and S. isognathus) were obtained by direct cytological preparations from kidney samples according to the methods given by Foresti et al. [33].

\section{Chromosome microdissection and DNA amplification}

Chromosome suspensions were dropped onto moist, 1\% SDS- cleaned coverslips. The coverslips were washed in $1 \mathrm{x}$ PBS solution for 1 minute and incubated in a trypsin solution ( $35 \mathrm{~mL} \mathrm{1x}$ PBS and $5 \mathrm{~mL}$ trypsin) for 30 seconds, washed again in $1 \mathrm{x}$ PBS and stained with Giemsa $1 \%$ in PBS.

The microdissection was performed using an Eppendorf TransferMan NK2 (Eppendorf) coupled to a Zeiss Axiovert 40 CFL microscope, with glass needles made with a Nikon puller and sterilized by UV radiation. About 8 chromosomes were separately placed in 9uL DNAse-free ultrapure water and were then amplified using the GenomePlex Single Cell Whole Genome Amplification Kit (WGA4-Sigma).

\section{Fluorescent in situ hybridisation (FISH)}

The probes were labelled using the GenomePlex (WGA3 Reamplification KIT-Sigma) following the manufacturer's protocol, except changing the kit dNTP mix for a $1 / 2 \mathrm{~T}$ dNTP mix and adding a biotin 16-dUTP in the reaction.

Fluorescent in situ hybridisation (FISH) was performed using the protocol described by Rens et al. [34,35] with several modifications.

Slides were dehydrated through an ethanol series; aged for $1 \mathrm{~h}$ at $60^{\circ} \mathrm{C}$, denatured in $70 \%$ formamide/0.6x salinesodium citrate (SSC) at $65^{\circ} \mathrm{C}$ for 2 minutes and dehydrated again. $3 \mu \mathrm{L}$ of biotinylated probe combined with L. elongatus Cot $1(2 \mu \mathrm{g})$ was precipitated in ethanol and resuspended in $13 \mu \mathrm{L}$ of hybridisation buffer (40\% deionized formamide (v/v), 10\% dextran sulfate, $2 \mathrm{x}$ SSC, $0.05 \mathrm{M}$ phosphate buffer, $\mathrm{pH}$ 7.3). This mixture was denatured for $10 \mathrm{~min}$ at $65^{\circ} \mathrm{C}$, pre-annealed at $37^{\circ} \mathrm{C}$ for 1 hour and applied to each slide. Hybridisation was carried out at $37^{\circ} \mathrm{C}$ for 12 hours for the same species and over three nights for cross species experiments. It was used Cot1 once that Fish genomes possess a high amount of repetitive elements and FISH with chromosome specific probes gives a large amount of background signal if no suppression of repetitive elements is used. Post-hybridisation washes were performed in $40 \%$ formamide/1.8x SSC twice for $5 \mathrm{~min}$ each, followed by 2x SSC twice for $5 \mathrm{~min}$ each and $4 \mathrm{x}$ SSC with $0.05 \%$ Tween-20 (4xT) once for $4 \mathrm{~min}$ at $42^{\circ} \mathrm{C}$ for the same species and $45^{\circ} \mathrm{C}$ for cross species. 
Probe detection was carried out using $200 \mu \mathrm{L}$ of diluted (1:500) Cy3-streptavidin antibody (Amersham) per slide at $37^{\circ} \mathrm{C}$ for $30 \mathrm{~min}$. After detection, slides were washed in $4 \mathrm{xT}$ three times for $3 \mathrm{~min}$ each at $42^{\circ} \mathrm{C}$ and mounted in Vectashield mounting medium with 4',6diamidino-2-phenylindole (DAPI; Vector Laboratories).

Images were captured and processed using the CytoVision Genus system (Applied Imaging, USA) and a Cohu CCD camera mounted on an Olympus BX-60 microscope.

\section{Competing interests}

The authors declare that they have no competing interests.

\section{Authors' contributions}

PPPM, FD, WR conceived and designed the experiments. PPPM and ELS performed the experiments and drafted the manuscript. WR and FD helped in cell culture and with developing the laboratory techniques. PCMO gave important suggestions about cell culture and FISH analysis. VT made substantial contributions in microdissection experiments. Most of the experiments were performed in MAFS laboratory. All authors read and approved the final manuscript.

\section{Acknowledgements}

The authors are grateful to Fundação de Amparo a Pesquisa do Estado de São Paulo - FAPESP and Coordenação de Aperfeiçoamento de Pessoal de Nível Superior - CAPES for the financial support. They also thank Instituto Brasileiro do Meio Ambiente e dos Recursos Naturais Renováveis (IBAMA) for the licensing of collection to ELS.

\section{Author details}

'Departamento de Biologia, Laboratório de Citogenética, Instituto de Biociências, Universidade Estadual Paulista "Julio de Mesquita Filho" - UNESP, Rio Claro, Av. 24A, 1515, CEP 13506-900 Rio Claro, SP, Brazil. 'Department of Veterinary Medicine, University of Cambridge, Cambridge Resource Centre for Comparative Genomics, Madingley Road, CB3 OES Cambridge, UK. ${ }^{3}$ Institute of Molecular and Cellular Biology, Siberian Branch of the Russian Academy of Sciences, Novosibirsk, Russia.

Received: 15 March 2013 Accepted: 1 July 2013

Published: 3 July 2013

\section{References}

1. Ohno S: Sex chromosomes and sex-linked genes. Berlin: Springer; 1967.

2. Charlesworth D, Charlesworth B, Marais G: Steps in the evolution of heteromorphic sex chromosomes. Heredity 2005, 95:118-128.

3. Vyskot B, Hobza R: Gender in plants: sex chromosomes are emerging from the fog. Trends Genet 2004, 20:432-438.

4. Ospina-Álvarez N, Piferrer F: Temperature-dependent sex determination in fish revisited: prevalence, a single sex ratio response pattern, and possible effects of climate change. PLOS ONE 2008, 3(7):2837.

5. Schultheis C, Böhne A, Schartl M, Volff J, Galiana-Arnoux D: Sex determination diversity and sex chromosome evolution in poeciliid fish. Sex Dev 2009, 3:68-77.

6. Devlin $\mathrm{RH}$, Nagahama Y: Sex determination and sex differentiation in fish: an overview of genetic, physiological, and environmental influences. Aquaculture 2002, 208:191-364.

7. Herpin A, Schartl M: Molecular mechanisms of sex determination and evolution of the $\mathrm{Y}$ chromosome: Insights from the medaka fish (Oryzias latipes). Mol Cell Endocrin 2009, 306:1-2

8. Hattori RS, Murai Y, Oura M, Masuda S, Majhi SK, Sakamoto T, Fernandino I, Somoza GM, Yokota M, Strussmann CA: A Y-linked anti-Mullerian hormone duplication takes over a critical role in sex determination. Proc Natl Acad Sci US 2012, 109(8):2955-9.

9. Cioffi MB, Sánchez A, Marchal JA, Kosyakova N, Liehr T, Trifonov V, Bertollo $L A C$ : Cross-species chromosome painting tracks the independent origin of multiple sex chromosomes in two cofamiliar Erythrinidae fishes. BMC Evolutionary Biology 2011, 11:1-10.
10. Takehana Y, Hamaguchi S, Sakaizumi M: Different origins of ZZ/ZW sex chromosomes in closely related medaka fishes, Oryzias javanicus and $O$. hubbsi. Chrom Res 2008, 16:801-811.

11. Tanaka K, Takehana Y, Naruse K, Hamaguchi S, Sakaizumi M: Evidence for different origins of sex chromosomes in closely related Oryzias fishes: substitution of the master sex-determining gene. Genetics 2007, 177:2075-2081.

12. Ota K, Kobayashi T, Ueno K, Gojobori T: Evolution of heteromorphic sex chromosomes in the order Aulopiformes. Gene 2000, 23:25-30.

13. Volff $J \mathrm{~N}$, Schartl M: Variability of genetic sex determination in Poeciliid fishes. Genetica 2001, 111:101-110.

14. Nakayama I, Foresti F, Tewari R, Schartl M, Chourrout D: Sex chromosome polymorphism and heterogametic males revealed by two cloned DNA probes in the ZW/ZZ fish Leporinus elongatus. Chromosoma 1994, 103:31-39.

15. Parise-Maltempi PP, Martins C, Oliveira C, Foresti F: Identification of a new repetitive element in the sex chromosomes of Leporinus elongatus (Teleostei: Characiformes: Anostomidae): new insights into the sex chromosomes of Leporinus. Cytogenet Gen Res 2007, 116:218-223.

16. Silva EL, Busso AF, Parise-Maltempi PP: Characterization and genome organization of a repetitive element associated with the nucleolar organizer region in Leporinus elongatus (Anostomidae: Characiformes). Cytogenet Gen Res 2013, 139:22-28.

17. Galetti PM, Foresti F, Bertollo LAC, Moreira Filho O: Karyotypic similarity in three genera (Leporinus, Leporellus, Schizodon) of the family Anostomidae (Pisces, Teleostei). Brazil J Genet 1981, 4:11-15.

18. Galetti PM, Lima NRW, Venere PC: A monophyletic ZW sex chromosome system in Leporinus (Anostomidae, Characiformes). Cytologia 1995, 60:375-382.

19. Venere PC, Ferreira IA, Martins C, Galetti PM: A novel ZZ/ZW sex chromosome system for the genus Leporinus. (Pisces, Anostomidae, Characiformes). Genetica 2004, 121:75-80

20. Marreta ME, Faldoni FLC, Parise-Maltempi PP: Cytogenetic mapping of the W chromosome in the genus Leporinus (Teleostei, Anostomidae) using a highly repetitive DNA sequence. J Fish Biol 2012, 80:630-637.

21. Silva EL, Borba RS, Parise-Maltempi PP: Chromosome mapping of repetitive sequences in Anostomidae species: implications for genomic and sex chromosome evolution. Molecular Cytogenetics 2012, 5:45-52.

22. Ferreira IA, Oliveira C, Venere $P$, Galetti PM, Martins C: 5 S rDNA variation and its phylogenetic inference In the genus Leporinus (Characiformes: Anostomidae). Genetica 2007, 129:253-257.

23. Nanda I, Benisch P, Fetting D, Haaf T, Schmid M: Synteny conservation of chicken macrochromosomes 1-10 in different avian lineages revealed by cross-species chromosome painting. Cytogenet Gen Res 2011, 132:165-181.

24. Ferguson-Smith MA, Trifonov V: Mammalian karyotype evolution. Nat Rev Gene 2007, 8(12):950-62.

25. Graphodatsky AS, Trifonov VA, Stanyon R: The genome diversity and karyotype evolution of mammals. Mol Cytogenet 2011, 4:22.

26. Phillips RB, Konkol NR, Reed KM, Stein D: Chromosome painting supports lack of homology among sex chromosomes in Oncorhynchus, Salmo and Salvelinus (Salmonidae). Genetica 2001, 111:119-123.

27. Takehana $Y$, Naruse K, Hamaguchi S, Sakaizumi M: Evolution of ZZ/ZW and $\mathrm{XX} / \mathrm{XY}$ sex-determination systems in the closely related medaka species, Oryzias hubbsi and O. dancena. Chromosoma 2007, 116:463-470.

28. Takehana Y, Demiyah D, Naruse K, Hamaguchi S, Sakaizumi M: Evolution of different $Y$ chromosomes in two medaka species, Oryzias dancena and O. latipes. Genetics 2007, 175:1335-1340.

29. Henning F, Moysés CB, Calcagnotto D, Meyer A, Almeida-Toledo LF: Independent fusions and recent origins of sex chromosomes in the evolution and diversification of glass knife fishes (Eigenmannia). Heredity 2011, 106:391-400.

30. Diniz D, Laudicina A, Cioffi MB, Bertollo LAC: Microdissection and whole chromosome painting: Improving sex chromosome analysis in Triportheus (Teleostei, Characiformes). Cytogenet Gen Res 2008 122:163-168.

31. Vicari MR, Artoni RF, Moreira-Filho O, Bertollo LAC: Diversification of a ZZ/ ZW sex chromosome system in Characidium fish (Crenuchidae, Characiformes). Genetica 2008, 134:311-317.

32. Pansonato-Alves JCP, Vicari MR, Oliveira C, Foresti F: Chromosomal diversification in populations of Characidium cf. gomesi (Teleostei, Crenuchidae). J Fish Biol 2011, 78:183-194. 
33. Foresti F, Oliveira C, Almeida-Toledo LF: A method for chromosome preparations from large specimens of fishes using in vitro short treatment with colchicine. Experientia 1993, 49:810-813.

34. Rens W, O'Brien PC, Yang F, Graves JA, Ferguson-Smith MA: Karyotype relationships between four distantly related marsupials revealed by reciprocal chromosome painting. Chromosome Res. 1999, 7:461-74.

35. Rens W, Moderegger K, Skelton H, Clarke O, Trifonov V, Ferguson-Smith MA: A procedure for image enhancement in chromosome painting. Chromosome Res 2006, 14:497-503.

doi:10.1186/1471-2156-14-60

Cite this article as: Parise-Maltempi et al: Comparative analysis of sex

chromosomes in Leporinus species (Teleostei, Characiformes) using chromosome painting. BMC Genetics 2013 14:60.

\section{Submit your next manuscript to BioMed Central and take full advantage of:}

- Convenient online submission

- Thorough peer review

- No space constraints or color figure charges

- Immediate publication on acceptance

- Inclusion in PubMed, CAS, Scopus and Google Scholar

- Research which is freely available for redistribution 